\title{
Efficacy and safety of combined piroxicam, dexamethasone, orphenadrine, and cyanocobalamin treatment in mandibular molar surgery
}

\footnotetext{
A.B. Barroso, V. Lima,

G.C. Guzzo, R.A. Moraes, M.C. Vasconcellos,

M.M. Bezerra, F.A.L. Viana,

R.C.R. Bezerra, G.S.M. Santana, F.A. Frota-Bezerra,

M.O. Moraes and M.E.A. Moraes
}

Unidade de Farmacologia Clínica, Departamento de Fisiologia e Farmacologia, Faculdade de Medicina, Universidade Federal do Ceará, Fortaleza, CE, Brasil
Correspondence

M.E.A. Moraes

Rua Cel. Nunes de Melo, 1127

60420-270 Fortaleza, CE

Brasil

Fax: +55-85-3223-2903

E-mail: betemora@ufc.br

Research supported by CNPq and by Instituto Claude Bernard-InCB, Brazil.

$\ldots \ldots \ldots \ldots \ldots \ldots$

Received November 29, 2005 Accepted July 17, 2006

\begin{abstract}
Third molar extraction is a common procedure frequently accompanied by moderate or severe pain, and involves sufficient numbers of patients to make studies relatively easy to perform. The aim of the present study was to determine the efficacy and safety of the therapeutic combination of $10 \mathrm{mg}$ piroxicam, $1 \mathrm{mg}$ dexamethasone, $35 \mathrm{mg}$ orphenadrine citrate, and $2.5 \mathrm{mg}$ cyanocobalamin $\left(\right.$ Rheumazin $\left.^{\circledR}\right)$ when compared with $20 \mathrm{mg}$ piroxicam alone (Feldene ${ }^{\circledR}$ ) in mandibular third molar surgery. Eighty patients scheduled for removal of the third molar were included in this randomized and double-blind study. They received ( $v o$ ) Rheumazin or Feldene $30 \mathrm{~min}$ after tooth extraction and once daily for 4 consecutive days. Pain was determined by a visual analogue scale and by the need for escape analgesia (paracetamol). Facial swelling was evaluated with a measuring tape and adverse effects and patient satisfaction were recorded. There was no statistically significant difference in facial swelling between Rheumazin and Feldene (control group). Both drugs were equally effective in the control of pain, with Rheumazin displaying less adverse effects than Feldene. Therefore, Rheumazin appears to provide a better risk/ benefit ratio in the mandibular molar surgery. Since the side effects resulting from nonsteroidal anti-inflammatory drug administration are a severe limitation to the routine use of these drugs in clinical practice, our results suggest that Rheumazin can be a good choice for third molar removal treatment.
\end{abstract}

\section{Introduction}

Pain after third molar extraction has become the model most frequently used in acute pain trials. The reason is that third
Key words

- Piroxicam

- Dexamethasone

- Orphenadrine

- Cyanocobalamin

- Pain

- Mandibular molar surgery 
swelling resulting from the surgery are generally caused by different factors, such as surgical trauma or endotoxins, which are treated with various therapeutic agents, including nonsteroidal anti-inflammatory drugs (NSAIDs, e.g., piroxicam, diclofenac, celecoxib), antibiotics, and others (2).

Various doses of piroxicam (5 to $40 \mathrm{mg}$ ) have been tested for postoperative dental pain. Although neither 5 nor $10 \mathrm{mg}$ piroxicam produced clinically significant analgesia, higher doses were significantly superior to placebo, and both the 20- and 40-mg doses were comparable to $648 \mathrm{mg}$ aspirin during the initial $6 \mathrm{~h}$. Piroxicam at 20 and $40 \mathrm{mg}$ produced a significantly longer duration of analgesia than did $648 \mathrm{mg}$ aspirin, and the analgesic effect of piroxicam appears to last for up to $24 \mathrm{~h}$ in a substantial number of patients (3). However, 20 or $40 \mathrm{mg}$ piroxicam induces the typical side effects of this drug class such as gastroduodenal hemorrhagic episodes or renal function damage.

The combination of piroxicam, dexamethasone, orphenadrine citrate, and cyanocobalamin can reach several targets. Piroxicam and dexamethasone can inhibit the activity of cyclooxygenases and phospholipase $\mathrm{A}_{2}$, respectively $(4,5)$. These effects result in reduced synthesis of prostaglandins and leukotrienes, which are involved in the inflammatory process. Orphenadrine citrate has analgesic properties and is used as a muscle relaxant in physical therapy to relieve pain and discomfort caused by strains, sprains, and other muscle injuries (6). Vitamin $\mathrm{B}_{12}$, also called cyanocobalamin, is an especially important vitamin for maintaining healthy nerve cells, and contributes to the production of DNA and RNA responsible for genetic expression (7). It may also improve conditions for DNA synthesis, promoting a quick recovery of injured tissue after surgery (8).

The objective of the present study was to determine the efficacy and safety of the therapeutic combination of $10 \mathrm{mg}$ piroxicam, 1 mg dexamethasone, $35 \mathrm{mg}$ orphenadrine citrate, and $2.5 \mathrm{mg}$ cyanocobalamin (Rheumazin $^{\circledR}$ ) in comparison to $20 \mathrm{mg}$ piroxicam $\left(\right.$ Feldene $^{\circledR}$ ) alone in a mandibular third molar surgery, evaluating pain and swelling.

\section{Material and Methods}

\section{Patients}

Eighty healthy adults, 25 men and 55 women requiring removal of mandibular third molars, participated in the study. All patients had their healthy condition confirmed by clinical and laboratory examinations. They had not taken any medication in the previous 3 months that might affect inflammatory responses, had no systemic diseases, did not consume alcohol, did not smoke, nor did they have any other condition that might interfere with the results. In addition to these systemic parameters, the position of the tooth, as described in the study design, was also used as an inclusion criterion. The study was approved by the Ethics Committee of the Federal University of Ceará. The study was conducted according to the 196/96 resolution from the Brazilian Ministry of Health.

All participants were made aware of the possible risks and benefits of the study, and informed written consent was obtained from them. The patients included in the study were aged 15 to 65 years, able to swallow tablets, and able to cooperate adequately with the trial procedure. All women were required to have a negative pregnancy test at least 15 days before the surgery (9).

\section{Study design}

A prospective, randomized, controlled, double-blind clinical trial was carried out to determine the efficacy and adverse events of the use of a combination of $10 \mathrm{mg}$ piroxicam, $1 \mathrm{mg}$ dexamethasone, $35 \mathrm{mg}$ orphenadrine citrate, and $2.5 \mathrm{mg}$ cyanocobalamin (Rheumazin $^{\circledR}$; Catafarma, Tubarão, SC, Brazil), or 
using single-agent $20 \mathrm{mg}$ piroxicam (Feldene $^{\circledR}$; Pfizer, São Paulo, SP, Brazil) as the positive control. The surgeries, considered to be moderately difficult on the basis of the tooth position, were carried out using standard procedures. A panoramic radiograph was obtained to determine the position of the tooth. We chose patients who had erupted, partially erupted or impacted molars in combination with any classical position according to the Winter (10) or the Pell and Gregory classification (11). Winter's classification shows a relationship between the inclination of the third molar and the distal surface of second molars (10), and the classification of Pell and Gregory is widely used to predict the difficulty of extracting impacted mandibular third molars. The classification of such molars is based on their spatial relationship (as shown by radiography) to the ascending ramus of the mandible and to the occlusal plane (11). Surgical time was estimated to be less than $40 \mathrm{~min}$.

In all surgical dental extractions, 2\% mepivacaine containing epinephrine (1: $100.000 ; 2 \%$ Scandicaine ${ }^{\circledR}$; Septodont, SaintMaur-des-Fossés, Cedex, France) was used for local anesthesia according to the technique of direct mandibular intraoral anesthesia. Osteotomy with a 702 broach and simultaneous irrigation with physiological solution were applied when necessary.

Each patient received one tablet of Rheumazin or Feldene orally $30 \mathrm{~min}$ after the surgical procedure, and once daily for the following 4 days. All medication was placed in identical envelopes and clearly marked with the initials of each patient. Analgesic efficacy was determined according to postoperative pain using a visual analogue scale and by the amount of paracetamol (750 mg) taken as escape analgesia (Tylenol; JanssenCilag, São Paulo, SP, Brazil), whenever the patient deemed it necessary, while the swelling was assessed using a calibrated metric scale as described later (12).

Pain scores were measured preoperatively (basal data) and at the 6, 24, 48, 72, and 120 $\mathrm{h}$ after treatment using a visual analogue scale. This scale has 10 levels that represent all pain sensations from none to maximum, where 0 indicates no pain, 1-9 indicate increasing pain (mild to moderate intensity), and 10 corresponds to intolerable (severe) pain. Pain scores were determined during the daily visits to the clinic (13). Patients were asked to place a mark along the line that corresponded to the amount of pain they were experiencing (14).

During the study, patients were allowed to take escape analgesia (750 $\mathrm{mg}$ paraceta$\mathrm{mol}$ ), if necessary, to relieve pain not controlled by the medications studied. The quantity of paracetamol was calculated in grams over the 5 days of study, with a maximum dose of $3 \mathrm{~g}$ of drug per day. The need for more than $6 \mathrm{~g}$ of escape analgesia in the first $48 \mathrm{~h}$ constituted failure to respond to treatment and the patient was excluded from the study.

Immediately prior to anesthesia and surgery, all subjects were submitted to face measurements using a calibrated metric scale in millimeters, for later determination of facial swelling. This was done by taking the sum of measures between three standard points demarcated with permanent ink. The first measurement was from the lower ear lobe to the pogonion, passing through a third point corresponding to the mandibular third molar on the outside part of the cheek (Figure 1, broken line, A). The second was from the lower ear lobe to the labial commissure (Figure 1, solid line, B). The sum of these first measures was considered to correspond to the basal data for each subject. Measurements were then made at $6,24,48,72$, and $120 \mathrm{~h}$ after surgery and compared to the respective basal data for each subject. At each visit, patients receiving Feldene or Rheumazin were asked to report any discomfort during the study, besides adverse effects.

At the end of the study $(120 \mathrm{~h})$, the 
Figure 1. Tape measuring method for the evaluation of facial swelling. The first measurement was from the lower ear lobe to the pogonion, passing through a third point corresponding to the mandibular third molar on the outside part of the cheek (broken line, A). The second was from the lower ear lobe to the labial commissure (solid line, B). patients were asked to evaluate their treatment with regard to pain and swelling. The patients could classify their degree of satisfaction according to scores of $0,1,2,3$, or 4 as poor, moderate, good, very good, or excellent, respectively.

\section{Statistical analysis}

Data were analyzed statistically by twoway repeated measures ANOVA to determine if there was a significant difference $(\mathrm{P}$ $<0.05)$, followed by a $t$-test, with $\alpha$ level adjusted by the number of time points (Bonferroni correction).

\section{Results}

This randomized controlled clinical trial enrolled 80 subjects undergoing surgical extraction of mandibular third molars. Thirtynine patients with a mean age of 23.0 (15-

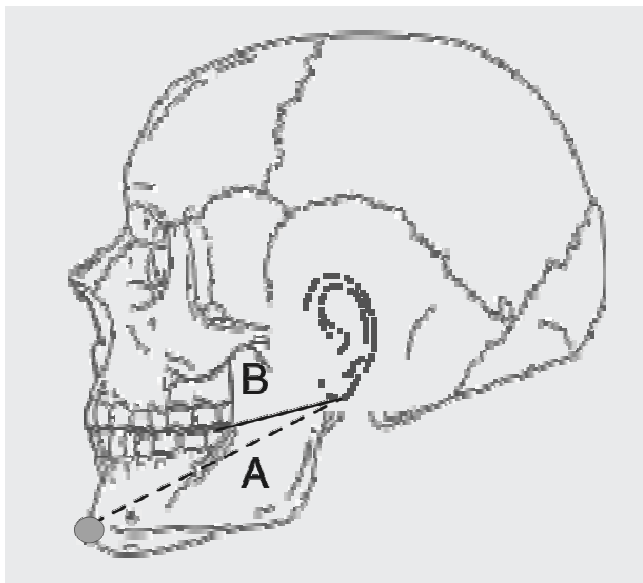

Figure 2. Time response curve for the development of postoperative pain as measured on a visual analogue scale. Patients receiving Feldene or Rheumazin were asked to report the intensity of pain indicating a visual analogue scale score of 0 to 10 at $6,24,48,72$, and $120 \mathrm{~h}$ after the surgical procedure. Data are reported as mean \pm SEM score. ${ }^{*} \mathrm{P}<0.05$ (two-way ANOVA; $t$ test)
50) years were included in the Rheumazin (R) group, and 41 patients with a mean age of 22.7 (16-43) years were included in the Feldene (F) group. Both groups were considered to be homogenous for age and gender, with no statistically significant difference between them (data not shown).

After surgery, significant differences were observed between the two groups. The maximum degree of pain was a score of 2 , and the prevalent scores were 0 or 1 . Although there was no significant difference between the two groups at other times, pain was significantly lower $(\mathrm{P}<0.05)$ in the Rheumazin group compared to the Feldene group at the 6 th and 120th hours (a score of 0 at $6 \mathrm{~h}(\mathrm{R}=$ $25, \mathrm{~F}=14)$ and at $120 \mathrm{~h}(\mathrm{R}=40, \mathrm{~F}=33$; Figure 2).

Interestingly, considering the amount of escape analgesia used, despite the lack of statistical difference, the use of paracetamol was also lower for the test (Rheumazin) group $(\mathrm{R}=0.15 ; 0.73-0.29)$, compared to Feldene $(\mathrm{F}=0.23 ; 0.13-0.31)$. These data are reported as median and range of values for escape analgesia.

Subjects were examined daily for swelling, and the measurements were reported in millimeters to determine changes compared to the basal level at the beginning of the study, which was equal to zero. The observation was that neither Rheumazin nor Feldene inhibited the swelling induced by the surgical procedure, a fact that became evident at the 6th hour. Thus, both drugs were similar regarding the control of facial swelling that persisted until the 120th hour ( $\mathrm{R}=5.03 ; 3.31-7.62)$, compared to Feldene $(\mathrm{F}=4.90 ; 2.18-5.90)$.

In addition, at each visit, patients receiving Feldene or Rheumazin were asked to report any discomfort during the study, besides adverse effects. Patients who received Feldene reported a larger number of adverse effects, including headache $(\mathrm{N}=3)$; gastric distress and nausea $(\mathrm{N}=2)$; sudorese, chills and fever $(\mathrm{N}=3)$; sleepiness and paresthesias 
$(\mathrm{N}=2)$, while only one patient who received Rheumazin reported moderate gastric pain.

At the end of the study, patients were asked to evaluate the treatment with regard to pain and swelling. The patients could rate the efficacy of the drug as poor, moderate, good, very good, or excellent. The Rheumazin group had higher scores than the Feldene group, with $95 \%$ of excellent (scores 3 and 4) or very good scores compared to $79.5 \%$ (scores 3 and 4 ) for the Feldene group. However, the difference was not statistically significant.

\section{Discussion}

The third molar post-extraction pain is one of the most representative models of acute post-surgical pain, and has been successfully used in recent years to assess the efficacy of different analgesic drugs (15). These surgical procedures result in the release of chemical mediators, increase nerve ending sensitivity and retention of a proteinrich fluid in the extravascular area (16). It has been reported that post-oral surgery pain is controllable with some NSAIDs such as piroxicam and other oxicams (17). Nevertheless, NSAIDs are sometimes ineffective in preventing swelling associated with pain (18). For this reason, the use of piroxicam combined with dexamethasone can be a good choice in terms of reducing the respective drug doses.

Acceptance of the use of glucocorticoids in dentistry to control post-surgical inflammation has been marred by concerns about side effects, adrenal suppression and efficacy. The mode of administration generally used is characterized as short-term, highdose or pulse therapy, which has not been associated with significant side effects or adrenal suppression beyond 10 days (19). Therefore, the use of steroids may inhibit the initial step in this process (20).

Rheumazin is a drug that contains half the concentration of piroxicam found in
Feldene, and is combined with a lower dose of dexamethasone $(1 \mathrm{mg})$ along with orphenadrine as a muscle relaxant and cyanocobalamin to improve nerve preservation. The use of drug combinations aimed at increasing the therapeutic potency and reducing the occurrence of possible adverse reactions is justified in order to improve patient treatment (21).

Therefore, the combination of piroxicam, dexamethasone, orphenadrine, and cyanocobalamin may improve the therapeutic response with regard to analgesic activity and reduction of inflammation (22). The use of NSAIDs in combination with dexamethasone has been shown to reduce the dose required to obtain the anti-inflammatory effect of the latter (23). NSAIDs are also known to modulate type III glucocorticoid receptors by increasing their number, which can potentiate the action of dexamethasone (24). This fact can also explain the therapeutic potency of Rheumazin compared to Feldene in the present trial, even though it contains half the amount of dexamethasone and piroxicam habitually used in regular treatments. In this context, orphenadrine could enhance the muscle relaxant effect of dexamethasone, while cyanocobalamin could contribute to the preservation and repair of nerve cells. It has been demonstrated that 2 mg dexamethasone can reduce pain and can reduce the need for analgesic drugs after tonsillectomy (25). The present clinical trial with Rheumazin showed that the combination of $10 \mathrm{mg}$ piroxicam requires only $1 \mathrm{mg}$ dexamethasone to relieve pain after third molar surgery, similar to Feldene, $20 \mathrm{mg}$ piroxicam. In addition, Rheumazin treatment required less use of escape analgesia after surgery, which can reduce the possibility of paracetamol hepatotoxicity (26).

On the other hand, dexamethasone may reduce the risk of hypersensitivity to piroxicam through immunosuppressive events leading to the inhibition of phospholipase $\mathrm{A}_{2}$ (27). Allergic reactions to NSAIDs may re- 
sult in the increased synthesis of leukotrienes, thus producing an antagonistic effect on cyclooxygenase activity (28).

Another event that can be observed after surgery for third molar removal is muscle spasm. Drugs that have muscle-relaxing activity combined with NSAIDs and analgesics may reduce muscle spasms after injurycausing procedures better than when used alone (29). The synergistic effect of the concomitant use of dexamethasone and piroxicam can lead to a reduction in the dose of orphenadrine since only a $35-\mathrm{mg}$ dose is present in the Rheumazin formulation (30).

All of the above mentioned events can contribute to patient recovery by replacing injured or dead tissue as a step toward wound healing (31). Therefore, certain substances need to be present at the injured area for optimal cell proliferation $(32,33)$. The presence of cyanocobalamin (vitamin $\mathrm{B}_{12}$ ) in Rheumazin is important due to its role as a co-enzyme in DNA synthesis, together with the presence of dexamethasone which has neuron protective activity (7).

The synergism between dexamethasone, piroxicam, orphenadrine citrate, and cyanocobalamin, according to the results obtained in the present trial, leads us to conclude that
Rheumazin can also be used for the control of the pain occurring after surgical trauma in third molar removal and that it could be a substitute for Feldene when indicated for postoperative treatment. Our results demonstrated equivalent therapeutic efficacy of Rheumazin at the dose evaluated when compared to the positive control Feldene. Corroborating the conclusion is the fact that when patients were asked to evaluate their treatment, $95 \%$ of those in the Rheumazin group gave scores of excellent or very good compared to $80 \%$ of those in the Feldene group. Regarding the lack of statistical difference between the effect of the drugs, we believe that this was probably due to the small number of participants in each group of this trial.

Both drugs showed the same effectiveness in the control of pain with Rheumazin displaying less adverse effects than Feldene. Therefore, Rheumazin may provide a better risk/benefit ratio in the mandibular molar surgery. Since the side effects resulting from NSAID administration are severe limitation to the routine use of these drugs in clinical practice, our results suggest that Rheumazin can be a good choice for third molar removal treatment.

\section{References}

1. Barden J, Edwards JE, McQuay HJ, Andrew MR. Pain and analgesic response after third molar extraction and other postsurgical pain. Pain 2004; 107: 86-90.

2. Khan AA, Brahim JS, Rowan JS, Dionne RA. In vivo selectivity of a selective cyclooxygenase 2 inhibitor in the oral surgery model. Clin Pharmacol Ther 2002; 72: 44-49.

3. Desjardins PJ. Analgesic efficacy of piroxicam in postoperative dental pain. Am J Med 1988; 84: 35-41.

4. Vane J, Botting R. Inflammation and the mechanism of action of antiinflammatory drugs. FASEB J 1987; 1: 89-96.

5. Vane JR, Botting RM. Mechanism of action of anti-inflammatory drugs. Scand J Rheumatol Suppl 1996; 102: 9-21.

6. Chou R, Peterson K, Helfand M. Comparative efficacy and safety of skeletal muscle relaxants for spasticity and musculoskeletal conditions: a systematic review. J Pain Symptom Manage 2004; 28: 140175.
7. Pittock SJ, Payne TA, Harper CM. Reversible myelopathy in a 34year-old man with vitamin B12 deficiency. Mayo Clin Proc 2002; 77: 291-294.

8. Hillman RS. Hematopoietic agents: growth factors, minerals, and vitamins. In: Hardman JG, Limbird LE, Gilman AG (Editors), Goodman and Gilman's the pharmacological basis of therapeutics. 10th edn. New York: McGraw Hill; 2001. p 1487-1517.

9. Patel A, Skelly AM, Kohn H, Preiskel HW. Double-blind placebocontrolled comparison of the analgesic effects of single doses of lornoxicam and aspirin in patients with postoperative dental pain. $\mathrm{Br}$ Dent J 1991; 170: 295-299.

10. Susarla SM, Dodson TB. Estimating third molar extraction difficulty: a comparison of subjective and objective factors. J Oral Maxillofac Surg 2005; 63: 427-434.

11. Garcia AG, Sampedro FG, Rey JG, Vila PG, Martin MS. Pell-Gregory classification is unreliable as a predictor of difficulty in extract- 
ing impacted lower third molars. Br J Oral Maxillofac Surg 2000; 38: 585-587.

12. Walton GM, Rood JP, Snowdon AT, Rickwood D. Ketorolac and diclofenac for postoperative pain relief following oral surgery. $\mathrm{Br} J$ Oral Maxillofac Surg 1993; 31: 158-160.

13. Hyrkas T, Ylipaavalniemi P, Oikarinen VJ, Paakkari I. A comparison of diclofenac with and without single-dose intravenous steroid to prevent postoperative pain after third molar removal. J Oral Maxillofac Surg 1993; 51: 634-636.

14. O'Brien TP, Roszkowski MT, Wolff LF, Hinrichs JE, Hargreaves KM. Effect of a non-steroidal anti-inflammatory drug on tissue levels of immunoreactive prostaglandin E2, immunoreactive leukotriene, and pain after periodontal surgery. J Periodontol 1996; 67: 1307-1316.

15. Olmedo MV, Vallecillo M, Gálvez R. Relación de las variables del paciente y de la intervención con el dolor y la inflamación postoperatorios en la exodoncia de los terceros molares. Med Oral 2002; 7: 360-369.

16. Roszkowski MT, Swift JQ, Hargreaves KM. Effect of NSAID administration on tissue levels of immunoreactive prostaglandin E2, leukotriene B4, and (S)-flurbiprofen following extraction of impacted third molars. Pain 1997; 73: 339-345.

17. Hart FD, Huskisson EC. Non-steroidal anti-inflammatory drugs. Current status and rational therapeutic use. Drugs 1984; 27: 232-255.

18. Ferreira SH. Peripheral analgesic sites of action of anti-inflammatory drugs. Int J Clin Pract Suppl 2002; 2-10.

19. Gersema L, Baker K. Use of corticosteroids in oral surgery. J Oral Maxillofac Surg 1992; 50: 270-277.

20. Montgomery MT, Hogg JP, Roberts DL, Redding SW. The use of glucocorticosteroids to lessen the inflammatory sequelae following third molar surgery. J Oral Maxillofac Surg 1990; 48: 179-187.

21. Kaitin KI, Manocchia M, Seibring M, Lasagna L. The new drug approvals of 1990,1991, and 1992: trends in drug development. J Clin Pharmacol 1994; 34: 120-127.

22. Schultze-Mosgau S, Schmelzeisen R, Frolich JC, Schmele H. Use of ibuprofen and methylprednisolone for the prevention of pain and swelling after removal of impacted third molars. J Oral Maxillofac Surg 1995; 53: 2-7.

23. Hirschelmann R, Poch G, Rafler I, Rickinger O, Giessler J. Steroidsaving potency of nonsteroidal antiinflammatory agents - a reevaluation with the new agent CGP 28238 in rat inflammatory models. Agents Actions Suppl 1991; 32: 51-57.

24. Golikov PP, Nikolaeva NI, Marchenko VV. Nonsteroidal antiinflammatory agents as modulators of glucocorticoid function of receptors. Vestn Ross Akad Med Nauk 1994; 47-52.

25. Stewart R, Bill R, Ullah R, McConaghy P, Hall SJ. Dexamethasone reduces pain after tonsillectomy in adults. Clin Otolaryngol Allied $\mathrm{Sci}$ 2002; 27: 321-326.

26. Meredith TJ, Vale JA. Non-narcotic analgesics. Problems of overdosage. Drugs 1986; 32 (Suppl 4): 177-205.

27. Goppelt-Struebe M. Molecular mechanisms involved in the regulation of prostaglandin biosynthesis by glucocorticoids. Biochem Pharmacol 1997; 53: 1389-1395.

28. Beutler B. TNF, immunity and inflammatory disease: lessons of the past decade. J Investig Med 1995; 43: 227-235.

29. Hunskaar S, Donnell D. Clinical and pharmacological review of the efficacy of orphenadrine and its combination with paracetamol in painful conditions. J Int Med Res 1991; 19: 71-87.

30. Troullos ES, Hargreaves KM, Butler DP, Dionne RA. Comparison of nonsteroidal anti-inflammatory drugs, ibuprofen and flurbiprofen, with methylprednisolone and placebo for acute pain, swelling, and trismus. J Oral Maxillofac Surg 1990; 48: 945-952.

31. Clark AJ, McLoughlin L, Grossman A. Familial glucocorticoid deficiency associated with point mutation in the adrenocorticotropin receptor. Lancet 1993; 341: 461-462.

32. Weissbach H, Taylor RT. Metabolic role of vitamin B12. Vitam Horm 1968; 26: 395-412.

33. Watanabe T, Kaji R, Oka N, Bara W, Kimura J. Ultra-high dose methylcobalamin promotes nerve regeneration in experimental acrylamide neuropathy. J Neurol Sci 1994; 122: 140-143. 